\title{
EFFECTS OF DOXORUBICIN ON LEFT VENTRICLE OF ADULT MALE ALBINO RATS: HISTOLOGICAL AND IMMUNOHISTOCHEMICAL STUDY
}

\author{
Khaled F, Ahmed F.E, Shaheen M.A and Mostafa S.A. \\ Department of Histology and Cell Biology, Faculty of Medicine, Zagazig University, Zagazig, \\ Egypt.
}

Samar Abdelaziz Mostafa, Email:

Samarmekawy289@yahoo.com

\begin{abstract}
Background/Aim:Doxorubicin (Dox) is one of the anthracyclines which are a group of antibiotics that are among the most active chemotherapeutic agents. It has a cardiotoxic effect. The objective of the study was to evaluate Dox as chemotherapeutic agent with cardiotoxic effect.

Methods: forty male wistar rats $(200 \pm 50 \mathrm{~g})$ were divided in to two groups: control and doxorubicin. Doxorubicin group was injected at a dose of $3 \mathrm{mg} / \mathrm{kg}$ BW of doxorubicin at days $1,3,5,7,9$ and 11 . At $12^{\text {th }}$ dayof the study, blood was collected by retro-orbital puncture and serum LDH and CK-MB were estimated. The animals were then sacrificed and their hearts were dissected and specimens were prepared and stained for histological examination by light microscope.

Results: Examination of H\&E sections of the left ventricular myocardium of Dox-treated group showed irregular separated cardiomyocytes with pyknotic nuclei and hemorrhage in-between. Sections of the same group revealed weak positive cytoplasmic immunoreactions for desmin protein in numerous cardiomyocytes. Intercalated discs and cytoplasmic striations also disappeared in several cardiomyocytes. Ultrathin sections of left ventricle of the Dox-treated group exhibited cardiomyocytes with irregular fragmented shaped nuclei and peripheral condensed chromatin with disorganized intercalated discs. Variable sized mitochondria with ruptured cristae were observed in between the fragmented myofibrils.

Conclusion: Dox showed evident harmful effects on left ventricular cardiocytes of adult male albino rats. Therefore, searches are required to find an alternative drug with the same efficacy or exploring protective methods against Dox hazardous impact on the heart.
\end{abstract}

Keywords: doxorubicin, cardiomyocytes, intercalated discs.

\section{INTRODUCTION}

$\mathrm{D}$ oxorubicin (Dox) is one of the anthracyclines which are a group of antibiotics that are among the most active chemotherapeutic agents (1).

Dox acts by many mechanisms in the cancer cell: by intercalation into DNA with disruption of DNA repair and by generation of free radicals and their harmful effects on the cellular membranes, DNA and proteins. Finally, it causes the activation of various molecular signals from AMPK (AMPactivated protein kinase inducing apoptosis) to

influence the Bcl-2/Bax apoptosis pathway. By altering the $\mathrm{Bcl}-2 / \mathrm{Bax}$ ratio, downstream activation of different caspases can occur resulting in apoptosis (2).
Metabolism of Dox within the mitochondria releases cytochrome-C which intiates apoptosis with disturbance in the mitochondrial calcium transport. Changes in calcium transport can lead to tissue injury and cardiacmyocytes killing with impairment in the cardiac contraction (3).

Li et al . (2002) reported that Dox damages the plasma membrane of cardiac myocytes and increase in antigen presenting dendritic cells with exaggerated immunological reaction to the heart cells (4).

So, this study aim to evaluate the effect of Dox on the left ventricle of the heart of adult male albino rats.

\section{MATERIALS AND METHODS}

\subsection{Drugs and chemicals}


-Dox: in the form of vial containing powder was reconstituted in $0.9 \%$ sodium chloride $(\mathrm{NaCl})$ at the concentration of $1 \mathrm{mg} / \mathrm{ml}$, divided into aliquots and kept frozen until use.

\subsection{Experimental animals}

Forty male Wistar rats were used in this experiment weighing $200 \pm 50 \mathrm{gm}$, purchased from Animal House, Faculty of Medicine, Zagazig University. They were housed in standard environmental condition and allowed free access to water and standard commercial food pellets.

\subsection{Experimental design}

-The animals used in the study were divided into 2 groups:

Group I: (control group): Twenty rats received $0.9 \%$ sodium chloride $(\mathrm{NaCl})$ at the concentration of $1 \mathrm{mg} / \mathrm{ml}-1$ at the same regimen of Dox (5).

Group II: (Dox- treated group):Twenty rats were injected I.V with Dox $3 \mathrm{mg} / \mathrm{kg}$ BW at days 1, 3, 5, 7, 9 and 11. It was obtained as a powder, dissolved in $0.9 \%$ sodium chloride $(\mathrm{NaCl})$ at the concentration of $1 \mathrm{mg} / \mathrm{ml}-1$ and were be divided into aliquots and kept frozen until use (5).

\subsection{Serologic assay:}

At $12^{\text {th }}$ dayof the study, blood was collected by retro-orbital puncture and serum LDH and CK-MB were estimated.

\subsection{Histological study:}

\section{5a. Light microscope study:}

The specimens were subjected to dehydration with alcohol of $70 \%, 90 \%$ and $100 \%$ strength each for 2 hours. Xylene was used for clearing. The embedding and impregnation were carried out by paraffin wax twice for each time for one hour. Parrafin blocks were prepeared. Specimens were cut into sections of 3,5 mm thickness and stained with H\&E.

\section{5a. Immunohistochemical reaction:}

The slides were deparaffinized in xylene, and rehydrated in graded ethanol. The endogenous peroxidase activity was blocked by incubation of sections for $30 \mathrm{~min}$ in $3 \% \mathrm{H} 2 \mathrm{O} 2$. The slides were covered by 2 drops normal rabbit serum and were incubated for $30 \mathrm{~min}$ in a humid chamber. The sections were incubated with mouse anti-insulin polyclonal antibody then the section was covered with biotinylated 50mg from (Royal Medical comp-Egypt).It secondary anti-immunoglobulin. One to two drops of labeling antibody (streptavidin enzyme label) were added to each section

\subsection{Statistical analysis:}

Statical analysis for morphological measurements. Image Analysis was done in Pathology Department, Faculty of Dentistry, Cairo University was used to: analyse H\&E and Sirus red-stained sections, calculate area $\%$ of collagen fibers and optical density of immunohistochemical-stained sections for desmin protein.

\section{RESULT \\ 3.1Statistical results: \\ -The area percent of collagen fibers:}

The mean values of the area percent of collagen fibers between the cardiomyocytes of adult male albino showed a high statistical significant difference between the studied groups. The area percent of collagen fibers in groupII increased ( table1).

-The optical density of immunoreactions for desmin protein :

The mean values of the optical density of Immunoreactions for desmin protein in the cardiomyocytes of adult male albino showed a high statistical significant difference between the studied groups. It increased in group II (table2).

\section{-The cardiomyocytes diameter:}

The mean values of the cardiomyocytes diameter of adult male albino rats showed a high statistical significant difference between the studied groups as regard fiber diameter, the least level showed in group II (DOX treated) (table3).

- The serological levels of cardiac markers(CPK,CK-MP and LDH):

The mean values of cardiac markers(CPK,CK-MP and LDH) levels in the blood of adult male albino rats showed a high statistical significant difference between the studied groups regarding bio-chemical changes occurred CPK, CK-MP and LDH, with a higher increase in group II (Doxtreated) in all parameters than group I(table4).

\subsection{Histological results:}

-Examination of H\&E-stained sections of in the left ventricular myocardium of control rats 


\section{Khaled et al...}

showed cardiac fibers arranged in transverse and longitudinal directions . They contained acidophilic sarcoplasm and oval central vesicular nuclei surrounded by perinuclear spaces. On the other hand, the left ventricular myocardium of Dox-treated group showed irregular separated cardiomyocytes with pyknotic nuclei and hemorrhage in-between (Fig.1)

Immunohistochemical-stained sections for desmin protein in control group revealed strong positive cytoplasmic immunoreactions for desmin which appeared mainly in intercalated discs and cytoplasmic striations. Sections of Dox group revealed weak positive cytoplasmic immunoreactions for desmin in numerous cardiomyocytes with disappearance of intercalated discs and cytoplasmic striations (Fig.2).

- Ultrathin sections of left ventricle of the control group revealed cardiomyocytes with

\section{Zagazig University Medical Journals}

euchromatic nuclei. Bundles of myofibrils were seen with rows of mitochondria lying between them. Myofibrils appeared with alternating dark (A) and light bands (I) bisected by $\mathrm{Z}$ lines. Myofibrils anastomosed at intercalated disk that had a transverse portion with adherens junction and a longitudinal portion with gap junction. Examination of the ultrathin sections of left ventricle of the Dox-treated group revealed cardiomyocytes with irregular fragmented shaped nuclei and peripheral condensed chromatin.Variable sized mitochondria with ruptured cristae were observed in between the fragmented myofibrils ( Fig.3)

-Ultrathin sections of control group showed myofibrils anastomosed at intercalated discs that had a transverse portion with adherens junction and a longitudinal portion with gap junction. Ultrathin sections of Dox group showed diorganized intercalated discs(Fig4).

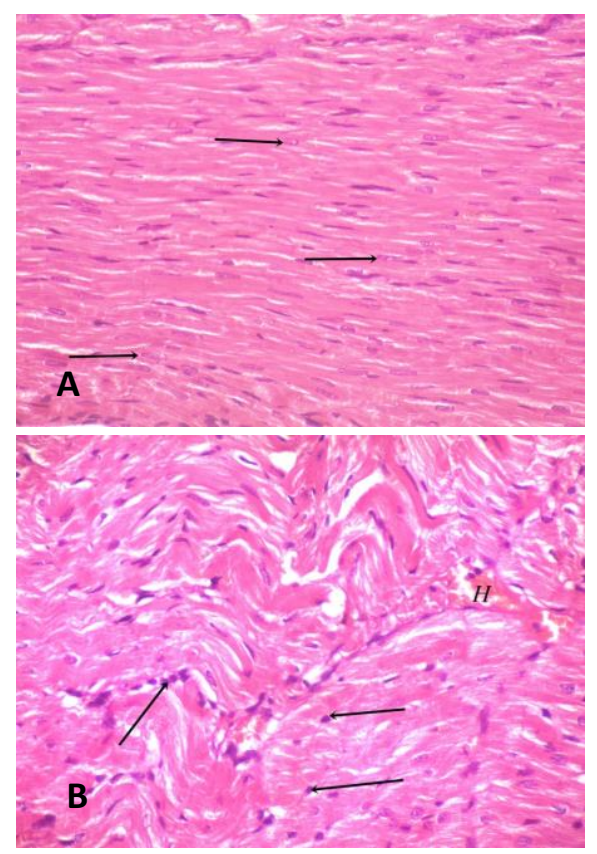

Fig.1: A) A photomicrograph of a section in the left ventricular myocardium of a control rat showing cardiomyocytes with acidophilic sarcoplasm and oval central vesicular nuclei (arrows).B) A photomicrograph of a section in the left ventricular myocardium of a Dox-treated rat showing cardiomyocytes with pyknotic nuclei (arrows) and hemorrhage $(\mathrm{H})$.

(H\&E, X 400) 


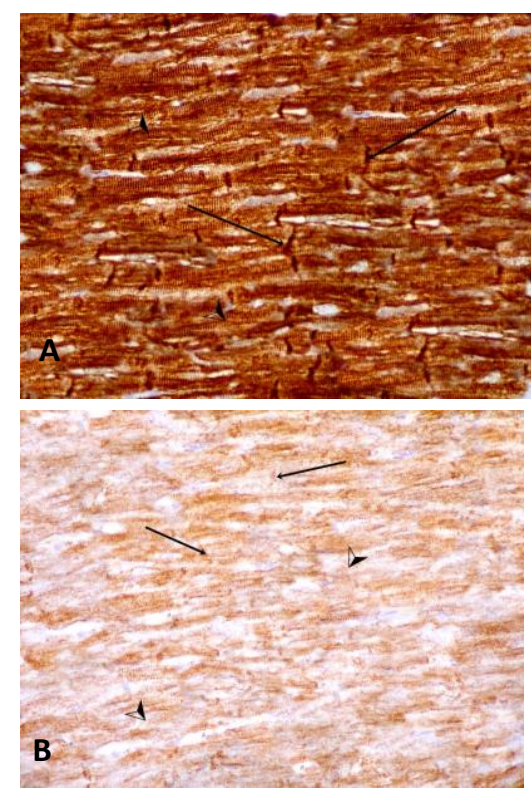

Fig.2:A) A photomicrograph of a section in the left ventricular myocardium of a control rat showing a strong positive cytoplasmic immunoreaction in intercalated discs (arrows). B) A photomicrograph of a section in the left ventricular myocardium of a Dox-treated rat showing weak positive cytoplasmic immunoreactions for desmin (arrows) and disappearance of intercalated discs and cytoplasmic striations (arrow heads).

(Immunoperoxidase for desmin filament, X 400).

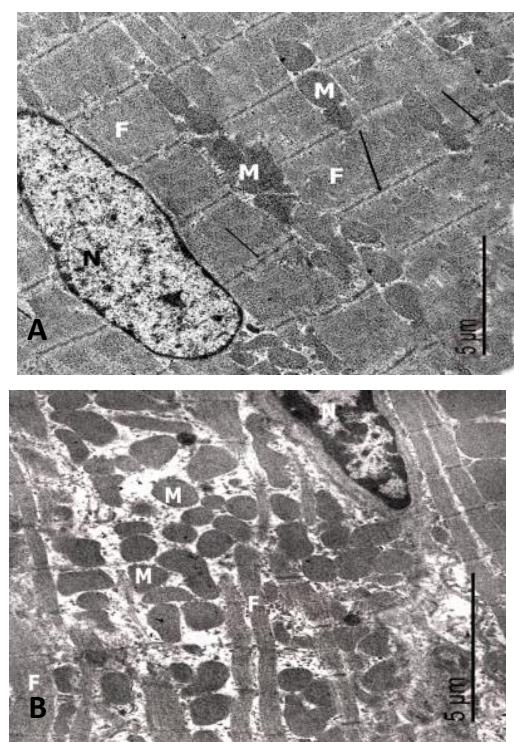

Fig.3: a) An electron micrograph from a section in the left ventricular myocardium of a control rat showing a cardiomyocyte with euchromatic nucleus $(\mathrm{N})$. Bundles of myofibrils are seen $(\mathrm{F})$ with rows of mitochondria (M) lying between them. Myofibrils appear with alternating dark (A) and light bands (I). Z lines (arrows) appear bisecting I bands. b) An electron micrograph from the left ventricular cardiomyocytes of Dox-treated rat showing heterochromatic nucleus $(\mathrm{N})$. Fragmentation of some of the myofibrils (F) with enlarged large number variable sized mitochondria (M) are seen. 


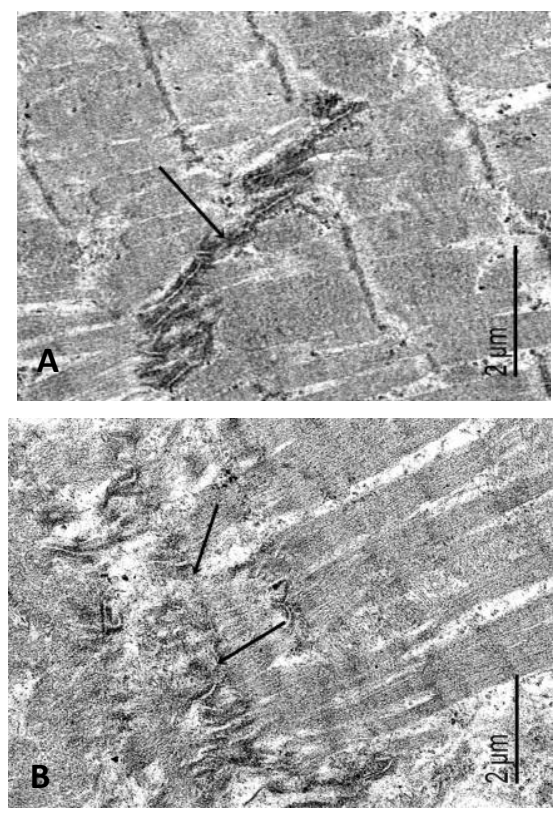

Fig.4:A) An electron micrograph from the left ventricular cardiomyocytes of a control rat showing anastomosing myofibrils at intercalated disk that has a transverse portion with adherens junction and a longitudinal portion with gap junction (arrow). B) An electron micrograph from the left ventricular cardiomyocytes of Dox-treated rat showing disrupted intercalated discs (arrow).

Table 1 Difference in area percent of collagen fibers between the studied groups.

\begin{tabular}{|c|c|c|c|}
\hline Variables & $\begin{array}{l}\text { Group I } \\
\mathrm{N}=10\end{array}$ & $\begin{array}{l}\text { Group II } \\
\mathrm{N}=10\end{array}$ & $\mathrm{P}$-value \\
\hline $\begin{array}{l}\text { Area percent } \\
\text { Mean } \pm \text { SD } \\
\text { Range }\end{array}$ & $\begin{array}{l}0.97 \pm 0.4 \\
0.5-1.83\end{array}$ & $\begin{array}{l}6.84 \pm 0.49 \\
6-7.43\end{array}$ & $<0.001$ \\
\hline
\end{tabular}

$\mathrm{P}$-value $<0.001$ is high significant

Table 2 Optical density for desmin protein between the studied groups:

\begin{tabular}{|c|c|c|c|}
\hline Variables & $\begin{array}{c}\text { Group I } \\
\mathrm{N}=10\end{array}$ & $\begin{array}{c}\text { Group II } \\
\mathrm{N}=10\end{array}$ & P-value \\
\hline Optical density & $85.7 \pm 4.8$ & $3.1 \pm 0.57$ & $<0.001$ \\
Mean \pm SD & $80.12-90.65$ & $2.33-3.94$ & \\
Range & & \\
\hline
\end{tabular}

$\mathrm{P}$-value $<0.001$ is highly significant 
Table 3 Fiber diameter between the studied groups:

\begin{tabular}{|l|l|l|l|}
\hline Variables & $\begin{array}{l}\text { Group I } \\
\mathrm{N}=10\end{array}$ & $\begin{array}{l}\text { Group II } \\
\mathrm{N}=10\end{array}$ & P-value \\
\hline $\begin{array}{l}\text { Fiber diameter } \\
\text { Mean } \pm \mathrm{SD} \\
\text { Range }\end{array}$ & $50.7 \pm 5.38$ & $23.1 \pm 1.37$ & $<0.001$ \\
\hline
\end{tabular}

$\mathrm{P}$-value $<0.001$ is highly significant

Table 4 Difference in bio-chemical changes between the studied groups.

\begin{tabular}{|l|l|l|l|}
\hline & $\begin{array}{l}\text { Group I } \\
\mathrm{N}=10\end{array}$ & $\begin{array}{l}\text { Group II } \\
\mathrm{N}=10\end{array}$ & P-value \\
\hline $\begin{array}{l}\text { CPK } \\
\text { Mean } \pm \text { SD } \\
\text { Range }\end{array}$ & $\begin{array}{l}\mathbf{4 6} \pm \mathbf{1 1 . 8} \\
\mathbf{3 3}-\mathbf{5 5}\end{array}$ & $\begin{array}{l}\mathbf{3 5 0 . 5} \pm \mathbf{5 1 . 1} \\
\mathbf{3 0 0}-\mathbf{4 1 0}\end{array}$ & $<\mathbf{0 . 0 0 1}$ \\
\hline CK-MP & $\mathbf{1 5 . 9} \pm \mathbf{1 . 7 9}$ & $\mathbf{4 2 . 6} \pm \mathbf{3 . 9}$ & $<\mathbf{0 . 0 0 1}$ \\
& $\mathbf{1 3}-\mathbf{1 8}$ & $765 \pm 50.99$ & $<0.001$ \\
\hline LDH & $277 \pm 33.7$ & $680-810$ & \\
\hline
\end{tabular}

$\mathrm{P}$-value $<0.001$ is highly significant

\section{DISCUSSION}

Malignant tumors incidence increases wide world. Unfortunately, chemotherapy has damage effects in the normal cells of the body organ mainly the heart (1).

Multiple trials investigated how to attenuate chemotherapy e.g Dox side-effects without interfering with its activity in tumor cells. Encapsulation of Dox by a liposomal membrane can decrease its cardiotoxicity (6).

In this study, the rats were divided into 2 groups: control and Dox treated- groups. The animals of Dox group were injected with Dox $(3 \mathrm{mg} / \mathrm{kg}$ BW at days $1,3,5,7,9$ and 11) (5).

In this study, significant statistical increase in CPK, LDH and CK-MB (the cardiac biomarker enzymes which are extensively used in the clinical practice as markers for the diagnosis of cardiac toxicity) of Dox group in comparison to the control group was reported (7).

Nuclear pyknosis observed in the Dox group cardiomyocytes with loss of striations was observed. Dox enters into DNA with disruption of DNA repair and generates free radicals with harmful effects on nuclear DNA and proteins (8).
Also, Apoptosis happens by the activation of various molecular signals from AMPK (AMP-activated protein kinase inducing apoptosis) and influence the Bcl-2/Bax apoptosis pathway (2).

Immunohistochemical stained sections showed weak positive cytoplasmic immunoreaction for desmin protein in the cardiac fibers with loss of the normal striations and z-line in the Dox group. Desmin expression decreases in the kidney of Dox treated rats. It can be explained by the destructive effect of Dox on the intracellular proteins including the desmin protein. direct cleavage from activated caspases during apoptosis (9).

Examination of the ultrathin sections of Dox treated group revealed cardiomyocytes with heterochromatic nuclei and peripheral condensed chromatin. Dox acts by disturbing the function of topoisomerases ( highly conserved enzymes that regulate DNA topology to facilitate DNA replication, transcription, and other nuclear processes), resulting in double-strand DNA break (10). Also, Dox treatment increases the level of ceramide (lipid molecule consisting of a sphingosine and a fatty acid that is involved 


\section{Khaled et al...}

in a variety of cellular processes including growth arrest, apoptosis, and senescence) which leads to nuclear fragmentation and cell damage (11).

Fragmented myofibrils observed in this groupthat reported. The decrease in myofibrillar bundles and degradation of sarcomeric titin was reported (12). The contractile filaments integrity is compromised on exposure to Dox in the heart with loss of sarcomeres and decreases contractile function which leads to subsequent heart failure (13).

Variable sized mitochondria with ruptured cristae were observed in between the fragmented myofibrils of Dox group. Mitochondrial size variability is explained by continuous replacement of damaged mitochondria by newly synthesized ones in order to sustain the constant need for ATPs (14).

Mitochondrial damage may be induced in many different ways: by impairing the respiratory chain, the Krebs cycle, the oxidative phosphorylation, as well as the fatty acid $\beta$-oxidation. They can also depend on the loss of the mitochondrial membrane potential, on the increased oxidative stress and on the reduced antioxidative capacity. Moreover, the mitochondrial DNA is proximal to the respiratory chain where most of the oxidative stress is produced (14).

Also, Dox binds the abundant phospholipid cardiolipin located in the inner mitochondrial membrane, which leads to mitochondrial accumulation of the drug. This would disrupt the electron transport chain and increases ROS production. It can interact directly with iron to form reactive anthracycline-iron complexes resulting in an iron cycling between $\mathrm{Fe} 3+$ and $\mathrm{Fe} 2+$ associated with ROS production. Therefore, the intramitochondrial accumulation of iron increase with more ROS production and mitochondrial damage (15).

\section{CONCLUSION}

Dox was proved to have a harmful effect on the histological structure of the left ventricular myocardium of adult Wister male albino rat.Therefore, patients using Dox need continous follow-up. Scientists need to find

\section{Zagazig University Medical Journals}

an alternative drug or finding protective method during Dox treatment.

Conflict of Interest: Non declared.

Funding: No funding sources

\section{REFERENCES}

1--Carvalho RA, Sousa RP , Cadete VJ , Lopaschuk GD, Palmeira CM, Bjork JA et al-.Metabolic remodeling associated with subchronic doxorubicin cardiomyopathy. Toxicology; 270:2009, 92-98.

2--Su H, Gorodny N, Gomez LF, Gangadharmath $\mathrm{U}, \mathrm{Mu} \mathrm{F}$, Chen G, Walsh JC, Szardenings K, Kolb HC and Tamarappoo B: Noninvasive molecular imaging of apoptosis in a mouse model of anthracycline-induced cardiotoxicity. Circ Cardiovasc Imaging; 2015: 8(2), e001952.

3-- Thorn CF, Oshiro C, Marsh S, HernandezBoussard T, McLeod H, Klein TE and Altman RB: Doxorubicin pathways: pharmacodynamics and adverse effects. Pharmacogenet Genomics; 2011: 21(7), 440446.

4- Li, T., Danelisen, I. and Singal, P.K.: Early changes in myocardial antioxidant enzymes in rats treated with adriamycin. Mol Cell Biochem; 2002: 232, 19-26.

5--Treat LH, McDannold N, Zhang Y, Vykhodtseva N, and Hynynen K: Improved anti-tumor effect of liposomal doxorubicin after targeted blood-brain barrier disruption by MRI-guided focused ultrasound in rat glioma. Ultrasound Med Biol; 2012: 38(10), 17161725.

6--Gabizon A, , Shmeeda H and Grenader $\mathrm{T}$ :Pharmacological basis of pegylated liposomal doxorubicin: Impact on cancer therapy. European Journal of Pharmaceutical Sciences; 2012: 45( 4), 388-398.

7-Singh D, Thakur A and Tang WH: Utilizing Cardiac Biomarkers to Detect and Prevent Chemotherapy-induced Cardiomyopathy. Curr Heart Fail Rep; 2015: 12(3), 255-262.

8- Barakat BM, Ahmed HI, Bahr HI and Elbahaie AM:Protective Effect of Boswellic Acids against Doxorubicin-Induced Hepatotoxicity: Impact on Nrf2/HO-1 Defense Pathway. Oxidative Medicine and Cellular Longevity ;2018:2018,10.

9--Wang $\mathrm{Z}$ and WansenSuna J: Effects of asiaticoside on levels of podocyte cytoskeletal proteins and renal slit diaphragm proteins in adriamycin-induced rat nephropathy. Life Sciences; 2013 :93(8), 352-358. 


\section{Khaled et al...}

10--Pommier Y, Leo E, Zhang H and Marchand $\mathrm{C}$ : DNA topoisomerases and their poisoning by anticancer and antibacterial drugs. Chem Biol; 2010:17,421-433.

11-Chen Q, Denard B, Huang $\mathrm{H}$ and Ye J: Epigenetic silencing of antiviral genes renders clones of Huh-7 cells permissive for hepatitis C virus replication. J Virol; 2013:87(1),659665.

12--Lim CC, Zuppinger C, Guo X, Kuster GM, Helmes M, Eppenberger HM, Suter TM, Liao $\mathrm{R}$ and Sawyer DB: Anthracyclines induce calpain-dependent titin proteolysis and necrosis in cardiomyocytes. J Biol Chem; 2004: 279(9),8290-8299.
Zagazig University Medical Journals

13-Arif IS, Hooper CL, Greco F, Williams AC and Boateng SY: Increasing doxorubicin activity against breast cancer cells using PPAR $\gamma$-ligands and by exploiting circadian rhythms. Br J Pharmacol; 2013: 169(5), 11781188.

14-Gorini S, Angelis AD, Berrino L, Malara N, Rosano $G$ and Ferraro E: Chemotherapeutic Drugs and Mitochondrial Dysfunction: Focus on Doxorubicin, Trastuzumab, and Sunitinib. Oxidative Medicine and Cellular Longevity; 2018, 15.

15-Huang H, Chen J, Lu H, Zhou M, Chai Z and $\mathrm{Hu}$ Y: Iron-induced generation of mitochondrial ROS depends on AMPK Activity. Biometals;2017 :30(4),623-628.

How to cite this article: Khaled F, Ahmed FE, Shaheen MA and Mostafa SA.Effects of Doxorubicin on Left Ventricle of Adult Male Albino Rats: Histological and Immunohistochemical Study.ZUMJ 2019; 25 (2); 242-249. DOI : 10.21608/ZUM].2019.25882 